\title{
Mortality and diabetes from a population based register in Yorkshire 1978-93
}

\author{
D P Warner, P A McKinney, G R Law, H J Bodansky
}

\begin{abstract}
Objective-To investigate mortality of children diagnosed with insulin dependent diabetes mellitus (IDDM) and to identify common factors before death.

Design-Follow up of a population based cohort of children diagnosed with IDDM to ascertain deaths.
\end{abstract}

Setting-Children were diagnosed in Yorkshire but followed up throughout the United Kingdom.

Subjects-From the Yorkshire Children's Diabetes Register details of 1854 children aged 0-16 years (1978-93) were submitted to the NHS Central Register.

Main outcome measure-Notification and causes of death.

Results-98.3\% of cases were traced and 26 deaths identified. Follow up ranged from 1-18 years (median 9.3 years), providing 17350 person-years of IDDM. Fifteen deaths $(58 \%)$ were attributed to diabetes or its complications; 11 (42\%) were unrelated and included one suicide. For mortality from all causes, the standardised mortality ratio (SMR) of 247 (95\% confidence interval (CI) 163 to 362) was significantly increased for those under 34 years. The largest number of deaths $(n=10)$ occurred in the 15-19 year age range, with an SMR of 442 (95\% CI 209 to 802). Case note examination showed a clear tendency towards poor diabetic control, and worries over control were expressed before death by health care professionals.

Diabetes Centre,

General Infirmary,

Leeds, UK

D P Warner

H J Bodansky

Paediatric

Epidemiology Group,

University of Leeds,

Leeds, UK

P A McKinney

Leukaemia Research Fund Centre for Clinical Epidemiology,

University of Leeds, Leeds, UK

G R Law

Correspondence to: Dr P A McKinney,

Paediatric Epidemiology Group, Centre for Health Services Research, University of Leeds, 32 Hyde Terrace, Leeds LS2 9LN, UK.

Accepted 1 December 1997 the "transition" age range.
(Arch Dis Child 1998;78:435-438)

Keywords: mortality; diabetes mellitus

Before the introduction of insulin treatment in the 1920s, childhood insulin dependent diabetes mellitus (IDDM) was a fatal condition, with an average survival of 20 months, ${ }^{12}$ death usually occurring from the effects of ketoacidosis. Since then continuing refinements in treatment and improved understanding of the condition have reduced both the overall mortality of the condition and the morbidity from its complications.

There have been several recent studies designed to examine mortality in people with IDDM..$^{3-6}$ Many of these have been conducted on restricted hospital based populations, possibly introducing bias into the results through selection of poorly controlled patients or those with complications. Few studies have looked at the age range between childhood and adulthood, when diabetes care is often in a state of transition between paediatric and adult diabetic clinics. This may be a particularly sensitive time and consideration of potential fatalities should not be forgotten in this age group.

A high quality register of incident cases of childhood IDDM was available from the Yorkshire region covering a varied population with long term follow up. ${ }^{7}$ This study aimed to examine patterns of mortality in this population based cohort of individuals diagnosed with IDDM during childhood, and to interpret clinical information available before death.

\section{Methods}

COHORT SELECTION

The Yorkshire Children's Diabetes Register records all children with insulin dependent diabetes diagnosed under the age of 17 years who were resident in the former Yorkshire Regional Health Authority at the time of initial diagnosis. Cases were ascertained from three independent sources: continuous reporting from all paediatricians, physicians with an interest in diabetes, and diabetes nurse specialists; general practitioner records; hospital discharge data. Capture-recapture calculations have estimated the register to be $97 \%$ complete. $^{78}$

The period 1978-93 was studied, yielding a cohort of 1854 cases, whose details were submitted to the NHS Central Register in Southport in July 1995 for determination of mortality status. Of this group, $98.3 \%$ of cases were successfully traced and 26 deaths were identified.

\section{CAUSE OF DEATH}

Causes of death were obtained from clinical notes, where available, and death certificates supplied by the NHS Central Register. No necropsy reports were available. Diabetes is generally underreported on death certificates $^{9}{ }^{10}$; however, it is likely to be omitted less often in the paediatric and adolescent population, where it is more directly responsible for death because there is usually less coexistent pathology. The follow up period for each person was calculated from the date of diagnosis to either death or the census date (31 July 1995). The duration of observation was 1-18 years (median 9.3 years), providing a total of 17350 person-years of IDDM.

Standardised mortality ratios (SMR) for deaths from all causes were calculated for all ages and 5 year age groups $(0-4, \ldots, 30-34)$ 
Table 1 Causes of death for Yorkshire Children's Diabetes Register 1978-93

\begin{tabular}{lclc}
\hline Cause of death & Male & Female & Total \\
\hline Diabetic ketoacidosis $^{\star}$ & 7 & 1 & 8 \\
Liver failure $_{\text {Accident }}$ & 3 & 0 & 3 \\
Hypoglycaemia $^{\star}$ & 2 & 1 & 3 \\
Diabetes (unspecified) $^{\star}$ & 1 & 2 & 3 \\
Malignant disease $_{\text {Pulmonary oedema }}^{\star}$ & 2 & 0 & 2 \\
Myocardial infarction $^{\star}$ & 2 & 0 & 2 \\
Suicide & 1 & 1 & 1 \\
Primary pulmonary HT & 1 & 0 & 1 \\
Cerebral palsy & 1 & 0 & 1 \\
Total & 1 & 0 & 1 \\
& 21 & 5 & 26 \\
\hline
\end{tabular}

${ }^{\star}$ Diabetes related deaths $(\mathrm{n}=15)$.

HT, hypertension.

comparing mortality in the selected cohort with annual age and sex specific rates in the general United Kingdom population. ${ }^{11}$ An SMR of 100 indicates a mortality identical to that expected from the general population; SMR values above and below 100 represent rates greater or less than expected. Ninety five per cent confidence intervals were calculated using Byar's approximation to the Poisson distribution. ${ }^{12}$ Numbers were insufficient to compute SMR values for deaths attributed to IDDM and its complications.

The hospital records were requested for the 26 patients who died. Nineteen sets of hospital case notes were made available $(73 \%)$. The remainder were either untraceable or had been destroyed by the records departments of the appropriate base hospitals. The case notes were systematically searched by one investigator in an attempt to identify underlying common features in the patients' case histories.

\section{Results}

There were 26 deaths (21 male and five female). On the basis of death certificate information and coded underlying causes of death, these were divided into fatalities that were considered to be either related or unrelated to diabetes. To fall into the first category the cause of death either had to be directly caused by a metabolic consequence of diabetes itself, or to be a result of the microvascular or macrovascular changes known to occur in diabetes. The identified factors included diabetic ketoacidosis and hypoglycaemic coma, myocardial infarction, pulmonary oedema following metabolic disturbance, and deaths secondary to diabetes where no further details were specified. Fifteen deaths (11 male and four female) were related to diabetes or to its vascular com- plications (table 1). Diabetic ketoacidosis was the primary cause of death in eight of the 26 deaths. Three patients died of hypoglycaemic episodes, and one patient suffered a fatal myocardial infarct.

In the group where death was felt to be unrelated to the underlying diagnosis of diabetes, three had inherited inborn errors of metabolism, of which diabetes was only one component (two of these were siblings); in each case liver failure was the primary cause of death. One death was attributed to primary pulmonary hypertension and one to cerebral palsy, and in both of these diabetes was a coexistent pathology. There was one case of suicide by deliberate ingestion of co-proxamol; the diagnosis of diabetes may have had a psychological role in this case, but no definite inference could be drawn from analysis of the case notes.

Review of the case notes showed a tendency for patients who died of diabetes related causes to have a more erratic degree of control. This is a largely clinical impression as estimations of average glycaemic control over long periods of time were not widely performed. Six of the eight patients who died from diabetic ketoacidosis had previous admissions to hospital in a ketoacidotic state. It was noted in half of these cases there had been concern about the degree of control achieved. In two cases the patient was at risk of acute metabolic complications as the family's concept of diabetic care was thought to be inadequate. Overall, the lack of data in the case notes precluded the completely systematic review originally planned. Nevertheless, it was possible to gain an impression of the clinical setting.

SMR values were calculated for all causes of mortality (table 2). Mortality was higher for subjects with IDDM for all ages combined (SMR 247; 95\% confidence interval (CI) 161 to 362), representing a significant increase $(p<0.0001)$ for those under 34 years of age. There was a notably high SMR for subjects aged $15-19$ years of 442 (95\% CI 212 to 813 ; small numbers result in wide confidence intervals).

\section{Discussion}

Despite advances in treatment, IDDM diagnosed in childhood still carries an increased mortality attributable to any cause. The mortality for all age groups from any cause of death was twice the expected rate compared with the United Kingdom as a whole. The risk

Table 2 Mortality for the Yorkshire Children's Diabetes Register compared with UK data

\begin{tabular}{|c|c|c|c|c|c|c|c|c|}
\hline \multirow[b]{2}{*}{$\begin{array}{l}\text { Age group } \\
\text { (years) }\end{array}$} & \multicolumn{3}{|c|}{ Yorkshire Children's Diabetes Register } & \multicolumn{3}{|c|}{ UK mortality statistics 1993} & \multirow[b]{2}{*}{$S M R$} & \multirow[b]{2}{*}{$95 \% C I$} \\
\hline & $\begin{array}{l}\text { No of deaths } \\
\text { (1978-95) }\end{array}$ & $\begin{array}{l}\text { Person-years } \\
(1978-95)\end{array}$ & $\begin{array}{l}\text { Rate } \\
\text { (100000/year) }\end{array}$ & No of deaths & Population & $\begin{array}{l}\text { Rate } \\
\text { (100000/year) }\end{array}$ & & \\
\hline $0-4$ & 3 & 678.74 & 442.0 & 5111 & 3433600 & 148.8 & 296 & 60 to 868 \\
\hline $5-9$ & 3 & 2652.67 & 113.1 & 461 & 3316000 & 13.9 & 814 & 164 to 2377 \\
\hline $10-14$ & 4 & 4619.33 & 43.3 & 574 & 3188000 & 18.0 & 241 & 27 to 868 \\
\hline $15-19$ & 10 & 5345.71 & 187.1 & 1269 & 2997900 & 42.3 & 442 & 212 to 813 \\
\hline $20-24$ & 4 & 2959.81 & 135.1 & 2115 & 3770400 & 56.1 & 241 & 65 to 617 \\
\hline $25-29$ & 4 & 1008.08 & 396.8 & 2532 & 4220200 & 60.0 & 661 & 178 to 1693 \\
\hline $30-34$ & 0 & 86.06 & 0 & 2982 & 3999000 & 74.6 & 0 & 0 to 0 \\
\hline Total & 26 & 17350.4 & 149.9 & 15044 & 24925100 & 60.6 & 247 & 161 to 362 \\
\hline
\end{tabular}

95\% confidence intervals (CI) calculated using Byar's exact approximation to the Poisson distribution. 
of dying from any cause for children diagnosed with IDDM is therefore double that expected in the general population. The excess risk was most pronounced at ages 5 to 9 years, with an SMR eight times the United Kingdom value, and between the ages of 25 and 29 years, with an SMR more than six times the expected. The largest number of deaths $(n=10)$ was in the transition phase between paediatric and adult diabetes health care (15-19 years). This adolescent group carried a fourfold excess risk of death over and above the general population. These data confirm findings from other studies. $^{3-6}{ }^{13-15}$ The number of deaths that occurred in the cohort was relatively small (26 of $1854 ; 17350$ person-years of IDDM) and reflects the good outcomes expected from northern European populations. ${ }^{16}$ The increased mortality in the 5-9,15-19, 20-24, and 25-29 year age groups was statistically significant but the width of the confidence intervals must convey caution in interpreting the data. Numbers were insufficient to compute formally SMR values for deaths attributable to IDDM and its complications, although detailed examination of the data can substantially assist with the conclusions to be drawn from the investigation.

Overall, $58 \%$ of deaths in this cohort were felt to be directly related to the underlying diagnosis of diabetes. Eleven deaths (42\%) during the period of follow up were from acute metabolic complications of IDDM-either hypoglycaemic episodes or factors associated with diabetic ketoacidosis. This is obviously of great concern. Recent research in the DCCT (diabetes control and complications trial) has shown that improved glycaemic control, as indicated by improving values for $\mathrm{HbA} 1 \mathrm{c}$, was associated with a decrease in the incidence of long term diabetic complications, albeit at the risk of increasing frequency of hypoglycaemic episodes. ${ }^{17}$ Three deaths occurred following an episode of hypoglycaemia; analysis of clinical records suggests that these deaths were not caused by a deliberate overdose of insulin. The "dead in bed" syndrome has previously been described, ${ }^{18}$ though none of the deaths in this study corresponded exactly to the description of this syndrome.

Deaths related to episodes of ketoacidosis were the most common. Eight deaths (35\%) fell into this category. On review, there was a tendency-perhaps not unsurprising-for these patients to have had a more erratic degree of control than in other cases, although this is a largely clinical impression as estimations of average glycaemic control were not widely performed in the late 1970s and 1980s when some of the cases were registered.

On several occasions the patient had previous admissions to hospital in a ketoacidotic state, and concern was noted before death about the degree of control achieved. In two cases it was felt that the child was at risk of acute metabolic complications, as the family's concept of diabetic care was deemed inadequate. This is an area where much attention is needed in the provision of childhood diabetic care, and it requires a thorough, sensitive multidisciplinary approach.

It may be possible to suspect which patients are at high risk from their diabetes, but the prognosis from episodes of ketoacidosis at the present time is favourable with recent mortality values of $7 \%(0-19 \%) .{ }^{19}$ Most patients recover from the acute episode. An uncommon and unpredictable complication of ketoacidotic coma in the paediatric population is cerebral oedema, which is associated with a poor prognosis. ${ }^{20}$ Two deaths in this study were attributable to this complication. These deaths show that diabetic ketoacidosis still has a definite mortality despite available treatment and health care.

Previous studies of diabetic mortality have noted a relatively low incidence of deaths from uraemia and end stage nephropathy. ${ }^{3}{ }^{4}$ The median follow up period of this study was 9.3 years (range 1-18 years), so in many cases nephropathy may not have had time to develop. Review of the case notes did not reveal any patients with significant deterioration of renal function or persistent proteinuria. Screening for microalbuminuria was not widespread during the greater proportion of the study.

The sex ratio of the Yorkshire Children's Diabetes Register was $56 \%$ male to $44 \%$ female. Of the 26 deaths, 21 occurred in males. The only category in which there were more female deaths was that of hypoglycaemia. It was difficult to ascertain whether these were accidental deaths or suicide attempts. These may have been parasuicide attempts that went wrong. It is well known that intentional drug overdose is very common among the population at large, especially in adolescent females. ${ }^{21}$ In terms of time to presentation there is obviously a much lower index of safety when insulin is taken in overdose than for other drugs. Interestingly, however, the only cause of death certified as suicide in the study was a male patient and did not involve insulin. Overall, although the numbers are small, proportionally more male patients died of ketoacidosis than female patients over the duration of the study. It would be interesting to compare the level of glycated haemoglobin in male and female patients to see if there is significantly worse control in male patients. Those patients certified as dying from diabetic ketoacidosis tended to have poor control, as previously noted.

\section{CONCLUSIONS}

Mortality rates in IDDM subjects remain higher than rates for non-diabetic people through early life and young adulthood. The transition from childhood to adolescent diabetic care is a period where supervision of care may be difficult, and this group of patients warrants careful surveillance. An unacceptably high proportion of deaths still occur secondary to acute metabolic complications of IDDM; this needs to be highlighted and borne in mind by professionals involved in diabetic care. Despite advances in care and refinements of insulin treatment, with the current emphasis on tight glycaemic control, diabetes still carries an unacceptably high mortality in young people. 
All the paediatricians, physicians, and general practitioners throughout Yorkshire are thanked for their active collaboration and support. We are grateful for the continued assistance of all the diabetes specialist nurses. This work has been financially supported by grants from the Children's Research Fund, Novo Nordisk, and The Special Trustees of the General Infirmary, Leeds. We are indebted to Carolyn Stephenson, Helen Lilley, and Nawal Ghali for data collection and processing. We thank Sheila Jones for her contribution to data handling and typing the manuscript.

1 Entmacher PS, Root HF, Marks HH. Longevity of diabetic patients in recent years. Diabetes 1964;13:373-7.

2 Krolewski AS, Warram JH, Christleib AR. Onset, course, complications, and prognosis of diabetes mellitus. In: Marble A, Krall LP, Bradley RF, et al, eds. Foslin's diabetes mellitus, 2nd ed. Philadelphia: Lea and Febiger, 1985:253-4.

3 McNally PG, Raymond NT, Burden ML, et al. Trends in mortality of childhood-onset insulin-dependent diabetes mellitus in Leicestershire: 1940-1991. Diabetic Med 1995; 12:961-6.

4 Dorman JS, LaPorte RE, Kuller LH, et al. The Pittsburgh insulin-dependent diabetes mellitus morbidity and mortality study. Diabetes 1984;33:271-6.

5 Green A, Hougaard P. Epidemiological studies of diabetes mellitus in Denmark: mortality and causes of death among mellitus in Denmark: mortality and causes of death among

6 Borch-Johnsen K, Kreiner S, Deckert T. Mortality of type 1 (insulin-dependent) diabetes mellitus in Denmark: a study of relative mortality in 2930 Danish type 1 diabetic patient diagnosed from 1933 to 1972. Diabetologia 1986;29:767-72.

7 Staines A, Bodansky HJ, Lilley HEB, Stephenson C, McNally RJQ, Cartwright RA. The epidemiology of diabetes mellitus in the United Kingdom: the Yorkshire Regional Childhood Diabetes Register. Diabetologia 1993; 36:1282-7.

8 Hook E, Regal R. Validity of Bernoulli census, log-linear and truncated binomial models for correcting for underestimates in prevalence studies. Am f Epidemiol 1982;116: 168-76.
9 Andersson DKG, Svardsudd K. The value of death certification statistics in measuring mortality in persons certification statistics in measuring mortality in persons
with diabetes. Scand f Prim Health Care 1994;12:114-20.

10 Whittall DE, Glatthaar C, Knuiman MW, Welborn TA. Deaths from diabetes are under-reported in national mortality statistics. Med $\mathcal{F}$ Aust 1992;152:598-600.

11 Office of Population Censuses and Surveys. Mortality statistics; cause. Review of the Registrar General on deaths by cause, sex and age, in England and Wales. London: HMSO, 1993.

12 Breslow NE, Day NE. Statistical methods in cancer research, vol II. The design and analysis of cohort studies. Lyon: IARC, 1987.

13 Deckert T, Poulsen JE, Larsen M. Prognosis of diabetics with diabetes onset before the age of thirty one. Diabetologia 1978;14:363-70

14 Swerdlow AJ, Jones ME. Mortality during 25 years of follow-up of a cohort with diabetes. Int $\mathcal{f}$ Epidemiol 1996;25:1250-61.

15 Modan M, Karp M, Bauman B, Gordon O, Danon Y, Laron $Z$. Mortality in Israeli Jewish patients with type 1 (insulindependent) diabetes mellitus diagnosed prior to 18 years of age: a population based study. Diabetologia 1991;34:51520 .

16 Matsushima M, LaPorte RE, Maruyama M, et al. Geographic variation in mortality among individuals with graphic variation in mortality among individuals with
youth-onset diabetes mellitus across the world. Diabetologia youth-onset diabe

17 The Diabetic Control and Complications Research Group. The effect of intensive treatment of diabetes on the development and progression of long-term complications in IDDM. N Engl 9 Med 1993;329:977-86.

18 Thordarson $\mathrm{H}$, Sovik O. Dead in bed syndrome in young diabetic patients in Norway. Diabetic Med 1995;12:782-7.
Pickup J, Williams G. Textbook of diabetes. Oxford: Blackwell,

19 Pickup

20 Rosenbloom AL, Riley WS, Weber FT, Malone JI, Donelly WH. Cerebral oedema complicating diabetic ketoacidosis in childhood. F Pediatr 1981;96:357-61.

21 Gelder M, Gath D, Mayou R, Cowen P. Oxford textbook of psychiatry. Oxford: Oxford University Press, 1996. 